\title{
RESERVAS EXTRATIVISTAS SEM EXTRATIVISMO: UMA TENDÊNCIA EM CURSO NA AMAZÔNIA?
}

Josimar da Silva Freitas

Doutor em Desenvolvimento Socioambiental

Universidade Federal do Pará - UFPA

Belém - Pará - Brasil

josimarfreitas55@gmail.com

Milton Cordeiro Farias Filho

Doutor em Desenvolvimento Socioambiental

Universidade da Amazônia - UNAMA

Belém - Pará - Brasil

mcffarias@gmail.com

\author{
Alfredo Kingo Oyama Homma \\ Doutor em Economia Aplicada \\ Empresa Brasileira de Pesquisa Agropecuária - EMBRAPA \\ Belém - Pará - Brasil \\ alfredo.homma@embrapa.br \\ Armin Mathis \\ Doutor em Ciências Políticas \\ Universidade Federal do Pará - UFPA \\ Belém - Pará - Brasil \\ armin.mathis@gmail.com
}

\section{RESUMO}

Temporalmente, as Reservas Extrativistas (Resex) perdem identidade de Unidades de Conservação de uso sustentável, à medida que os resultados se apresentam insustentáveis. Nestes termos, avaliamos os resultados das políticas estatais, os sistemas produtivos e os impactos ambientais que impedem alcançar conservação e desenvolvimento. Este estudo é importante porque poucas literaturas discutem esta temática, e as que foram enunciadas até o momento não avaliam o modelo a partir da presença Estatal, dos sistemas de produção e dos impactos ao meio ambiente, portanto, oriundos destas interrelações. Essa pesquisa foi desenvolvida por meio do estudo de associação com interferência, onde algumas variáveis dependeram de outras, e, além do mais, foram aplicados formulários semiabertos e entrevistas livres. Aqui, concluímos que as Resex são insustentáveis porque estas áreas foram criadas para conservação ecossistêmica, e não para melhoria de vida de milhares de famílias. De igual modo, a insustentabilidade de conservação e o desenvolvimento acontece em detrimento do abandono, da repressão e exclusão estatal.

Palavras-chave: Agricultura; Amazônia; Desflorestamento; Extrativismo; Pecuária.

\section{EXTRACTIVE RESERVES WITHOUT EXTRACTIVISM: A TREND ONGOING IN THE BRAZILIAN AMAZON?}

\begin{abstract}
The Brazilian Extractive Reserves (Resex) lose identity of Conservation Units of sustainable use, as their results are unsustainable. In these terms, we evaluated the results of government policies, production systems and environmental impacts that prevent conservation and development of the reserves. This study is important since few articles discuss this theme, and the ones that have been stated so far do not evaluate the model from the government presence, the production systems and the impacts to the environment, therefore, arising from these inter-relationships. This research was developed through semi-open questionnaires and interviews in order to understand the association with interference, where some variables depended on others, and forms were applied semi-open and free interviews. We conclude that Resexs are unsustainable because these areas were created for ecosystem conservation instead of betterment of thousands of families. Similarly, unsustainability of conservation and development occurs due to the detriment of State abandonment, repression and exclusion.
\end{abstract}

Key words: Agriculture; Amazon; Deforestation; Extractivism; Livestock. 


\section{INTRODUÇÃO}

As primeiras Reservas Extrativistas ${ }^{1}$ (Resex) foram fundadas em 1990, com base na reivindicação proferida pelo movimento de seringueiros na década de 1980. A exigência foi contra a exploração desenfreada de fazendeiros que adentravam as áreas de seringais acreanos. As Resex representavam o resgaste da cultura, dos hábitos e costumes dos habitantes, bem como a convivência combinada de atividades extrativistas, roças e criação de animais.

Juridicamente, a Lei 7.804/1989 (art. $9^{\circ}, 18^{\circ}$ e $225^{\circ}$ ) amparava a criação de áreas com fins a conservação ambiental, responsabilidade ecossistêmica, produção extrativista, agrícola e criação de animais. Em termos institucionais, o Instituto Brasileiro do Meio Ambiente e dos Recursos Naturais Renováveis (Ibama) era responsável pelo gerenciamento, fiscalização e controle, à época da fundação das Resex. Os moradores acreditavam que as instituições estatais implementariam projetos sociais (saúde, educação, aposentadoria, entre outros) e incentivos aos sistemas de produção (crédito, assistência técnica, transporte e o mínimo de tecnologias), de modo assegurar equilíbrio ambiental e melhoria nas condições de vida.

Desde sua criação, as Resex estavam ancoradas em recursos externos e as organizações governamentais não assumiram a responsabilidade de geri-las. As Unidades de Conservação (UCs) ficaram sujeitas a um regime de proteção externa e o Estado brasileiro, mesmo sendo protagonista legal, se tornou condicionado às decisões do Programa Piloto para a Proteção das Florestas Tropicais do Brasil (PPG7) (Arruda, 1999).

Passados quase três décadas de fundação das primeiras Resex, o Estado nacional pouco fez para melhorar o bem-estar da famílias e dos recursos ambientais nessas áreas. Este estudo busca contemplar evidências que sustentam a ideia de que a política de criação de áreas protegidas como fator indutor do desenvolvimento sustentável na Amazônia fracassou. Quase 30 anos depois essa constatação é válida.

Dessa forma, a questão central da pesquisa está baseada nesta perspectiva: Por que as Resex da Amazônia não vêm produzindo resultados esperados a sustentabilidade? Pesquisas que discutem esta temática não avaliam o modelo de produção nas Resex a partir da presença de organizações estatais, suas ações e análise dos sistemas produtivos nessas áreas. Esses enunciados justificam a relevância deste estudo.

\section{AVALIAÇÃO DAS EXPERIÊNCIAS DE RESEX NA LITERATURA ACADÊMICA}

A seleção de trabalhos publicados sobre esse tema teve como critério o período de 1990 e 2016. O período de início se justifica por ser o ano de criação das primeiras Resex brasileiras na Amazônia: Acre, Amapá e Rondônia. Foram priorizados artigos e excluídos dissertações, teses, documentos técnicos, relatórios, resumos de congressos, anais e artigos de jornais.

A seleção foi realizada em duas bases de textos nacionais (Periódicos Capes e Scielo) e 11 internacionais (Annual Reviews, Cambridge Journals Online, Ebsco, Jstor, Nature, Web of Science, Wiley Online Library, World Scientific, Science Direct, Springer e Scopus) de maio a junho de 2016, publicados em português, espanhol e inglês. A seleção de texto obedeceu aos critérios do modelo Prisma. Além de ser baseado em evidências, várias abordagens têm sido desenvolvidas para conduzir revisões sistemáticas em amplo conjunto de questões (Moher et al., 2009).

Foram priorizados trabalhos com temas ambientais, econômicos, sociais, institucionais e territoriais que tratam de Resex. Foram excluídos os que tratavam de reservas de indústrias minerais, etnobotânica, ecossistemas marinhos, biodiversidade animal e Unidades de Conservação de Proteção Integral ou de Uso Indireto. O foco foram as Resex.

Com o assassinato de Chico Mendes, em 22 de dezembro de 1988, pressões nacionais e externas aceleraram a criação de Resex, e estas foram consideradas a grande alternativa ambiental brasileira (Homma, 2014). Antes da criação das primeiras Resex, ambientalistas construíram conclusões avessas aos seringueiros. O olhar destes extrativistas-agricultores estava direcionado 
tanto para o meio ambiente, como para a defesa de muitos que haviam sido mortos e humilhados, na década de 1980. Um desses cientistas concluiu: a prioridade para demarcar o maior número de Resex deveria acontecer o mais rapidamente possível e, mais tarde, a melhoria nas condições de vida (Fearnside, 1989).

A criação de UC foi fundamental para assegurar eficácia institucional e equilíbrio ecológico (Benatti, 1998), constituir estratégias para a proteção da biodiversidade (Carregosa, Silva \& Kunhavalik, 2015), assegurar continuidade de processos ecológicos (Campos-Silva \& Peres, 2016), e minimizar perturbações aos monumentos arqueológicos (Silva, Fraxe \& Silva, 2015).

E, ainda, a maior ênfase das pesquisas efetuadas repousa na biodiversidade (Begon, Townsend \& Harper, 2005), no turismo como indutor de sustentabilidade (Coriolano \& Lima, 2003), e nas ações isoladas que, do ponto de vista micro, buscam construir argumentos insustentáveis nas evidências de Lage e Milone (2001). Os poucos estudos sobre extrativismo, criação bovina, agricultura e desflorestamento são discutidos separadamente (Homma, 2014, p. 14), bem como não avaliam o modelo de Resex.

Além desses argumentos, Allegretti (2008) acrescenta que a política de criação de áreas protegidas teve êxito politicamente porque criou um mecanismo institucional de resolução de conflitos em torno da terra e floresta; socialmente, porque assegurou meios de vida para gerações atuais e futuras; culturalmente, porque respeitou formas tradicionais de uso dos recursos naturais; e ambientalmente, porque impediu o avanço de desmatamentos (Allegretti, 2008). Essas proposições foram significativas na concepção e no início do modelo Resex, entretanto, perderam expressividade no decorrer do tempo.

Algumas justificativas relativizavam a criação dessas áreas, pois consideravam que a política de demarcação de Resex aconteceu sem prévio planejamento estratégico, o que prejudicou drasticamente as áreas social e ambiental. Ao contrário, quando bem-sucedidas, oferecem oportunidades econômicas aos grupos dessas áreas, mas não necessariamente protegem a floresta, porque dependem de respostas apropriadas às necessidades sociais (Browder, 1992).

Condições de base ecológica, econômica, política e cultural precisam ser compreendidas e incorporadas no que diz respeito às decisões sobre a viabilidade, o papel, a localização e extensão de Resex, bem como a implementação e gerenciamento de tais sistemas (Salafsky, Dugelby \& Terborgh, 1993). Desse modo, são claras as demonstrações de que as instituições brasileiras são frágeis para estabelecer sua missão, tal como a elaboração de políticas e estratégias para as Resex (Fantini \& Crisóstomo, 2009). Em particular, na Amazônia, a capacidade de conservar a biodiversidade, em face do aumento crescente de destruição de florestas, carece de mais compreensão (Levey, 2002).

A título de exemplo, as Resex enfrentam problemas para implantar o que foi orientado e/ou planejado pela política que a criou. Se o objetivo da política era garantir a viabilidade de Resex como uma forma sustentada na conservação, há pouca evidência de que os responsáveis políticos tivessem interesse suficiente para mudar a situação de bem-estar de habitantes (Goeschl \& Igliori, 2004).

$\mathrm{Na}$ prática, as Resex apenas alcançam bons resultados quando asseguram meios de vida sustentáveis aos moradores da floresta, com rendimentos elevados, acesso aos serviços de saúde e educação (Brown \& Rosendo, 2000). Quando isso não acontece, cria-se insegurança econômica, e as ações focadas na subsistência e reprodução social são direcionadas aos sistemas produtivos com maior valor de mercado.

E ainda, a ausência de alternativas de instituições estatais incentivam os moradores de Resex criarem formas produtivas que geram maior impacto ambiental (agricultura e pecuária extensiva). É o que confirma Siraj et al. (2016), os recursos florestais ofertam meios de subsistência aos pobres em todo o mundo, entretanto, práticas ilegais ocorrem em razão de pobreza extrema.

Os baixos investimentos e a equipe inexperiente para lidar com questões complexas compromete o bem-estar de famílias e a biodiversidade, portanto, os efeitos das ações institucionais cooperam com insucesso e põem em risco o futuro do modelo Resex. Nos termos de Riemann, 
Santesálvarez e Pombo (2011), os habitantes destas áreas enfrentarem precárias condições de vida. Goeschl e Igliori (2004) defendem que os responsáveis políticos não têm escopo suficiente para equilibrar conservação e melhorar a qualidade de vida dos moradores. E Silva e Simonian (2015) concluem que o Estado não proporciona políticas públicas eficazes que melhorem a situação de insubsistência que vivenciam essas populações (Silva \& Simonian, 2015).

Mesmo assim, o Estado continua adotando uma postura autoritária, com viés conservacionista e avessa à participação de populações locais no processo de gestão (Vivacqua \& Vieira, 2005). Essa deterioração vem modificando a ordem produtiva das Resex e esfacelando o modelo. Os limites biofísicos da natureza, sua capacidade de resiliência e sustentabilidade não logram progresso e comprometem gerações futuras (Carmo et al., 2016). A contradição entre conservação ambiental e desenvolvimento social existe, e poucas alternativas foram produzidas para amenizar esse desgaste.

Como alternativa, relações de confiança sustentadas por meio de relações democráticas entre gestores institucionais e moradores de Resex possibilitam eficiência em projetos de desenvolvimento social, produtivo e racionalidade ambiental. É o que asseguram Newton, Endo \& Peres (2011), políticas sociais e produtivas auxiliam gestores a realizar mudanças dentro de cenários demográficos e econômicos, para melhor utilização dos recursos disponíveis.

Nos termos de Homma (2010), a redução de destruição de recursos naturais da Amazônia irá depender muito mais do desenvolvimento de atividades agrícolas sustentáveis em áreas desmatadas, da coleta de produtos florestais e da venda de serviços ambientais. Outra possibilidade é aproveitar 76 milhões de hectares (áreas secundárias) com atividades produtivas adequadas à promoção e recuperação de áreas desflorestadas. Essa tendência ainda não ocorre em Resex da Amazônia (Homma, 2016).

\subsection{Os sistemas de produção de Resex cooperam com sustentabilidade?}

Há quase três décadas de existência, as Resex experimentaram sistemas de produção extrativista, agrícola e pecuário. No princípio, o extrativismo da borracha, castanha e óleos vegetais apresentou expressividade, mas, em curto período, cedeu espaço para agricultura e pecuária. Em casos específicos, como da população da Resex do Alto Juruá (Estado do Acre), o padrão de subsistência, organização e alianças são difíceis de manter a diversidade cultural e ecológica (Begossi et al., 1999).

Dependendo das políticas de apoio ao extrativismo, as fases de expansão e estabilização de coleta podem ser prolongadas e/ou até reduzidas com o surgimento de novas alternativas (Homma, 2014, p.17). Para Ross (2016), a efetivação de Pagamento por Serviço Ambiental (PSA) é uma possibilidade que propõe combinar conservação com desenvolvimento. E Francisco et al. (2008) asseguram que a atividade extrativista se torna competitiva e com efetividade conservacionista.

O extrativismo foi forte motivo para a criação de Resex, porém, a economia extrativista tem se mostrado limitada se comparada com a produção da pecuária e agricultura (Allegretti, 1994). A economia extrativa foi também a razão e a causa do declínio regional, apoiando-se na disponibilidade dos recursos naturais e na crença de sua inesgotabilidade (Homma, 2011). O extrativismo não sustenta as necessidades dos habitantes, e o desejo de manter a floresta em pé ocorrerá sob determinadas condições.

A tendência do extrativismo é de desaparecimento, considerando as condições que se encontra o mercado extrativista. Existem graves problemas em Resex, estes incluem mercados limitados para produtos florestais, vulnerabilidade às flutuações de preços e altos custos de transação, o que torna a autossuficiência econômica irrealista (Hall, 2004).

O Estado Brasileiro, desde a fundação das Resex, se comporta obedientemente as ofertas de alguns países, tais como Alemanha, Canadá, EUA, França, Itália, Japão, Reino Unido, Holanda e União Europeia. Estes têm políticas sem sustentabilidade (créditos de carbono), pois não conseguem reduzir as dificuldades sociais e econômicas dos moradores. Com o crescimento da 
oferta de serviços ambientais, o preço de carbono no longo prazo pode cair, indicando que este mercado pode ser vítima do seu próprio sucesso.

As Resex são influenciadas pelo mercado, uma vez que os valores e a produtividade de produtos florestais extrativos são menos competitivos, se comparado com outros sistemas produtivos. Apesar de o extrativismo possibilitar o modelo ideal de relação do homem com os recursos ambientais, seja pelo o simbolismo histórico da herança indígena ou pela ínfima pressão ecossistêmica, o mercado costuma medir a viabilidade. $\mathrm{O}$ que vem acontecendo é forte desgaste a produção extrativista, e isto fez com que muitos produtores substituíssem os recursos não madeireiros pela agricultura e pecuária, com amplo mercado de carne bovina, capacidade de multiplicação e como ativo financeiro.

A agricultura, por sua vez, é muito antiga, sobretudo quando avaliamos a produção de mandioca pelos indígenas há milhares de anos. Os indícios mostram que, há cerca de 3.500 anos, o cultivo da mandioca passou a ser uma prática adotada, possivelmente domesticada pelos tupis na Bacia Amazônica (Homma, 2003). Ademais, o conhecimento agrícola foi repassado historicamente às gerações, ao passo de os residentes a margem de estradas, rios e igarapés possuírem afinidade com a linha de produção agrícola.

Ainda, conforme Homma (2016), o uso parcial de áreas já desmatadas (76 milhões de hectares) com atividades produtivas adequadas reduziu desmatamento e queimadas em florestas primárias da Amazônia, mas é preciso analisar as políticas públicas mais amplas que favorecem o uso de áreas já desmatadas da região (Homma, 1996). Portanto, não é recente a proposta de racionalidade do uso da terra, principalmente, como meio de contribuir com a manutenção dos meios de vida dos habitantes e as formas tradicionais de utilização dos recursos naturais.

Contudo, a criação de Resex na Amazônia não induziu eficiente mudança para melhorar a degradação da floresta, e não há evidências consistentes de que haja medidas adequadas para reduzir ou gerar mudanças comportamentais de pequenos produtores (Carmenta et al., 2016). Por exemplo, atividades agrícolas e pecuárias são responsáveis pelo aumento de desflorestamento e queimadas efetuadas em Resex. Os que possuem mais tempo de residência em Resex conseguem recursos provindos do Programa de Fortalecimento da Agricultura Familiar (Pronaf) e os investimentos são direcionados aos dois sistemas de produção.

Além desse fato, as áreas de Resex dividem limites com fazendas bovinas e/ou bubalinas, ao passo de influenciar a entrada e o aumento de produção. Nas palavras de Gomes, Vadjunec e Perz (2012), a pecuária tem um produto mais fácil de vender e traz garantias de segurança para o produtor, e se consolida como retorno menos arriscado em Resex (Vadjunec \& Rocheleau, 2009).

A Reserva Extrativista Chico Mendes foi desmatada 6,3\% dos 970.570 hectares para acomodar 10 mil cabeças de gado, o que representa expansão de 11 vezes a área desflorestada para pastagem desde que a reserva foi criada, em 1990 (Peres, 2011). Esse é um dos motivos que eleva as taxas de desmatamento de áreas primárias.

Mais ainda, as famílias que moram em Resex estão encontrando dificuldades de subsistência, e isso contribui para intensificar e diversificar atividades de maior impacto (Maciel et al., 2010). O desmatamento, em nível doméstico, é realizado na agricultura e pecuária, consequentemente, por residentes de longa duração (Vadjunec, 2011). Portanto, por mais que a política ambiental das Resex seja única para Amazônia e o restante do Brasil, as realidades sociais, econômicas, ambientais e culturais são heterogêneas (Florentino, Silva \& Freitas, 2016).

Assim, as famílias que habitam em Resex estão com pouca representatividade política, baixa capacidade de influenciar no planejamento dessas áreas, e ainda são prejudicadas na renda para a subsistência (Santos \& Brannstrom, 2015). Diante do crescimento da agricultura e pecuária, o extrativismo não se sustenta e há perdas de recursos ambientais além de seu limite em Resex. O processo de "pecuarização" que dominou as décadas de 1970 a 1980, vem sendo substituído pelo processo de "agriculturização", ocupando áreas de pastos degradados com cultivos de grãos, a partir da década de 1990 (Homma, 2017). 


\section{MÉTODO E PROCEDIMENTO}

A pesquisa foi desenvolvida nas três das maiores Resex da Amazônia brasileira, cuja abrangência envolve territórios de vários municípios dos estados do Acre, Rondônia e Amapá. Foi realizado um survey com moradores das Resex e analistas ambientais, portanto, responsáveis pelo controle e pela fiscalização das três Resex. Além disso, em setembro de 2016 e janeiro a março de 2017, foram realizadas observações e atividades de coletas.

No campo, foi possível conversar e conhecer de perto as dificuldades dos habitantes, os modos de vida, a cultura, os costume e hábitos, bem como as atuações trabalhistas de coleta de castanhas, óleos vegetais, artesanatos, caça, pesca, agricultura e criação de animais. Além do mais, as frequentes situações problemas de educação: falta de escolas, professores, merenda e migração de crianças e adolescentes para centros urbanos; saúde: esporadicamente há atendimentos preventivos e/ou de enfermeiros, médicos e serviços odontológicos; transporte: apenas próprios e/ou por meio de fretamento. Estes são os principais desafios sociais que os moradores das Resex enfrentam constantemente.

Em termos de estrutura, o estudo foi desenvolvido em quatro etapas, a primeira corresponde a revisão de trabalhos publicados sobre UC, Resex e teoria econômica, que serviram de base para elaboração do método, resultados, discussão e conclusão.

\subsection{Seleção e caracterização das Resex}

Os levantamentos de campo foram desenvolvidos nas Resex Alto Juruá-AC, Rio Ouro Preto-RO e Rio Cajari-AP. A primeira, está localizada no município de Marechal Thaumaturgo, Estado do Acre, com 4.170 habitantes. A segunda, está localizada nos municípios de Guajará-Mirim e Nova Mamoré (ambos de Rondônia), e registram 699 habitantes. A terceira, está localizada nos municípios de Laranjal do Jari, Mazagão e Vitória do Jari (Amapá) e assinala 2.293 habitantes (Ibge, 2010).

Os dados da pesquisa de campo são sobre três sistemas produtivos presentes em todas as Resex estudadas, quais sejam: agricultura (farinha, arroz, milho, feijão, etc.), pecuária (criação de bovinos e bubalinos) e extrativismo (castanha, açaí, borracha e óleos vegetais). A ordem em que aparecem os sistemas produtivos é decrescente em função de sua importância na composição da renda das famílias.

\subsection{Técnicas e procedimentos de pesquisa}

Foi desenvolvido um survey (Babbie, 2003) com uso de formulários semiabertos com chefes de famílias (sexo masculino e feminino) que moram pelo menos 10 anos nas Resex. Este critério é justificado pela vivência na área e capacidade de fornecer informações relevantes à pesquisa.

Para preenchimento dos formulários, foi retirada uma amostra de 232 moradores nas três Resex (101, na Rio Cajari; 67, na Rio Ouro Preto e 64, na Alto Juruá). Os dados da Alto Juruá foram efetivados em 2012 e atualizados em 2017. Foram entrevistados (entrevista estruturada) 12 Analistas Ambientais do ICMBio Resex, sendo quatro para cada Resex.

Os formulários contemplaram questões ambientais, demográficas, econômicas, sociais e institucionais. Os grupos de questões apontaram perguntas concernentes a avaliação do modelo implementado pelo Estado das Resex. Na tentativa de aproximar as questões o mais próximo da realidade dos entrevistados, fizemos um teste em uma comunidade Quilombola (município de Inhangapi-PA), o que permitiu ajustar e corrigir alguns erros identificados.

Validado o instrumento de pesquisa, iniciamos as entrevistas. Nos dois casos, os entrevistados não foram identificados por nome e sim por posição que ocupam, tanto moradores como representantes comunitários. 
Os gestores entrevistados estavam lotados nos escritórios do Instituto Chico Mendes de Conservação da Biodiversidade (ICMBio) de Brasília-DF, Belém-PA, Macapá-AP, Porto VelhoRO, Guajará-Mirim-RO e Cruzeiro do Sul-AC. O objetivo foi entender a concepção de cada um dos entrevistados a partir de suas experiências institucionais, e, posteriormente, comparar com as informações informadas pelos moradores das Resex.

O levantamento de campo aconteceu em dois momentos. No primeiro (setembro/2016), foram feitas identificação e conversas com chefes e lideranças comunitárias das Resex. As conversas serviram para obtenção de informações sobre acesso, distâncias, deslocamentos, tempo para cada atividade e retorno dos resultados.

No segundo momento (janeiro a março/2017), foram realizadas entrevistas estruturadas com um roteiro constando 38 questões direcionadas aos moradores e 29 aos gestores. No momento das perguntas, gravávamos as entrevistas autorizadas, porque entendíamos que somente no campo somos capazes de romper as fronteiras de questões dos formulários.

\subsection{Delineamento do estudo e análise dos dados}

A pesquisa foi desenvolvida por meio do estudo de associação com interferência, onde algumas variáveis interferiram sobre outras. A título de exemplo, os moradores dependem de regras estabelecidas pelo Estado, isto é, para implementar roças, retirar madeiras, criar animais, caçar, pescar, etc. Para isso, como o trabalho é rudimentar e/ou sem tecnologia para desmatar e queimar em área primária ou secundária, é necessário autorização do Instituto Chico Mendes de Conservação da Biodiversidade (ICMBio). Para Volpato (2015), essa associação existe porque há dependência, e uma ou mais variáveis interferem sobre outras. Estes são apenas alguns exemplos para representação do método.

As análises dos dados dos formulários estão centradas nos resultados de indicadores estatísticos como média, mediana e moda, assim como possibilitou olhar os dados por diversos ângulos. Foram utilizadas referências que correspondem ao grupo ambiental, econômico, institucional e social, para assegurar as falas e/ou depoimento de habitantes e analistas ambientais do ICMBio, presentes nos resultados e na discussão.

\section{RESULTADOS E DISCUSSÃO}

Esta seção analisa dados referentes a agricultura, pecuária, ao extrativismo e desflorestamento, bem como o debate confirma ou refuta conclusões de pesquisadores.

\subsection{Sistemas de produção}

A ineficiência das Resex se mostra na renda das famílias nos três sistemas produtivos (extrativismo, agricultura e pecuária). O rendimento da produção extrativista foi inferior ao da agricultura e pecuária, certamente pela baixa produção, dificuldade mercadológica, pouca atenção e/ou parcos investimentos.

Fearnside (1989) chamava atenção para a necessidade de demarcação de Resex como sendo prioritário e o mais rápido possível, para depois buscar a melhoria nas condições de vida. Esta posição não se sustentou ao longo do tempo, pois o que os dados revelam é o extrativismo como fonte insuficiente de reprodução social das famílias e manutenção da floresta. Um dos entrevistados confirma isso:

(...) para nós, é muito trabalhoso discutir e trabalhar Resex, porque são áreas de alta complexidade (recursos financeiros insuficientes), e cada dia as demandas sociais e produtivas aumentam (Analista ambiental/ICMBio, Belém-PA, março, 2017). 
Não basta apenas criar áreas como se isso fosse condição para sustentabilidade em seu tripé. Deixar famílias submissas aos regimes jurídicos repressivos e sem efetivação de políticas sociais e produtivas, não resolve a base dessa sustentabilidade. Um dos entrevistados esclarece o contexto:

(...) Quiseram excluir as Resex, porque quem arrecada é parque, muito embora as reservas biológicas não sejam caras, são áreas de pesquisas (...). Na época do PPG-7, as Resex funcionavam bem, mas quando o dinheiro acabou, simplesmente parou de funcionar (Analista ambiental/ICMBio, Brasília-DF, fevereiro 2017).

(...) Hoje, recebo demandas de criação de Resex, mas o Estado não tem recursos para política de criação de unidades de conservação, o Estado nunca teve interesse em manter as ilhas de excelência, somente quando tinha recursos de fora (Analista ambiental/ICMBio, Brasília-DF, fevereiro 2017).

(...) E ainda, as Resex são reconhecimento de direitos territoriais, mas criamos e deixamos eles se virarem, eles já estão lá, por outro lado, quando temos previsão de recursos relativos (bolsa verde, bolsa família), que também é um apelo, que para mim não significa muita coisa, mas para eles representa muito (Analista ambiental/ICMBio, Brasília-DF, fevereiro 2017).

Essa situação relatada é sustentada por Arruda (1999) ao argumentar que as Unidades de Conservação ficaram sujeitas a um regime de proteção externa e, o Estado brasileiro, mesmo sendo protagonista legal, se tornou condicionado às decisões do PPG7.

Demarcar o maior número de áreas para preservação e não cuidar das condicionantes para a sustentabilidade, que é manter condições de sobrevivência compatíveis com a manutenção das florestas, parece ter sido a base das decisões estatais. Isso demonstra a fragilidade das instituições governamentais para estabelecer sua missão, tal como a elaboração de políticas e estratégias para as Resex (Fantini; Crisóstomo, 2009), além dessa dificuldade, desde o início da demarcação das reservas, Browder (1992) já chamava atenção para a necessidade de respostas adequadas às demandas sociais.

\subsection{Produção agrícola}

A agricultura de pequena escala e a criação bovina são os maiores sistemas de produção e rendimento das Resex analisadas. Perguntamos aos entrevistados, qual o rendimento oriundo deste sistema de produção. A classificação da renda de cada domicílio ficou estabelecida conforme os valores com base em salários mínimos (renda), o número de entrevistados (Tabela 1).

Tabela 1: Rendimento domiciliar mensal da agricultura nas três Resex

\begin{tabular}{|l|c|c|c|}
\hline \multicolumn{2}{|c|}{ Renda } & Frequência & \% \\
\hline \multirow{4}{*}{ Válidos } & Menos de 1/2 salário mínimo & 56 & 24,1 \\
\cline { 2 - 4 } & $1 / 2$ a 1 salário mínimo & 77 & 33,2 \\
\cline { 2 - 4 } & 1 a 1/2 salários mínimos & 14 & 6,0 \\
\cline { 2 - 4 } & $1^{1 / 2}$ a 2 salários mínimos & 7 & 3,0 \\
\cline { 2 - 4 } & 2 a 21/2 salários mínimos & 3 & 1,3 \\
\cline { 2 - 4 } & $2^{1 / 2}$ a 3 salários mínimos & 1 & 0,4 \\
\hline Sub Total & 158 & 68,1 \\
\hline Omissos & 74 & 31,9 \\
\hline Total & $\mathbf{2 3 2}$ & $\mathbf{1 0 0 , 0}$ \\
\hline
\end{tabular}

Fonte: Pesquisa de campo

A maior renda deste sistema de produção varia entre 0,5 a 1 salário mínimo $(48,7 \%)$. Por conseguinte, 56 dos entrevistados afirmaram que suas rendas são inferiores a 0,5 salário mínimo. Esses valores são insuficientes para obtenção de subsistência das famílias das Resex, sobretudo em 
moradias que residem mais de uma família. As rendas informadas são domiciliares e não per capita, portanto as famílias sobrevivem com muitas dificuldades.

A explicação da pressão humana aos recursos ambientais é a necessidade de subsistência. As precárias condições de vida dos habitantes destas áreas condicionam atividades produtivas que causam degradação ambiental (Riemann, Santesálvarez \& Pombo, 2011). Os entrevistados demonstram as dificuldades e o descontentamento com a situação atual das Resex pesquisadas:

(...) A estrutura do ICMBio é baixa, tanto do ponto de vista de recursos humanos quanto financeiros, o que dificulta alcançar metas ambientais e melhoria de vida das famílias da Resex (Analista ambiental/ICMBio, Macapá-AP, março 2017).

As Resex devem ser vistas a partir de um ponto de vista mais pragmático e deveriam ter agendas pontuais para desencadear agendas maiores, ou seja, não excluir populações de viverem de modo positivo (Analista ambiental/ICMBio, Brasília, fevereiro 2017).

(...) Além do mais, o Estado nunca esteve interessado em investir em unidades de conservação, no governo Lula o discurso imposto é que nós não precisamos de recursos internacionais, nós temos capacidade de arrecadar para manter (Analista Ambiental/ICMBio, Brasília-DF, fevereiro 2017).

Em linhas gerais, a redução da destruição dos recursos naturais na Amazônia depende mais do desenvolvimento de atividades agrícolas sustentáveis em áreas desmatadas, a que da coleta de produtos florestais e venda de serviços ambientais (Homma, 2010). O Estado continua adotando uma postura autoritária, com viés preservacionista e avesso à participação de populações locais no processo de gestão (Vivacqua \& Vieira, 2005). Não basta impedir, de maneira repressora, as pessoas que trabalham na agricultura, o Estado deve efetivar alternativas viáveis para o desenvolvimento destas.

\subsection{Produção bovina e/ou bubalina}

A produção pecuária (bovino e bubalino) se iguala, em termos de renda, com a agricultura e supera o extrativimo (castanha, açai, borracha e óleos vegetais). A média de renda proveniente da pecuária nas Resex ficou entre 0,5 a 1,0 (16,4\%) salário mínimo (Tabela 2). Os omissos e/ou perdidos somam $75,4 \%$ de 57 entrevistados, ou 175 dos 232 entrevistados não participam deste tipo de produção nas Resex, mesmo assim sua renda é superior ao da produção extrativista.

Os entrevistados justificaram que esta atividade representa uma poupança para a "hora de necessidade" (66,7\%), assim como tem bom preço e é fácil de vender (10,5\%). Essa atividade econômica é incompatível com a manutenção da floresta e a tendência é de crescimento, porque as instituições estatais perderam controle.

Tabela 2: Rendimento domiciliar mensal da pecuária nas três Resex

\begin{tabular}{|l|c|c|c|}
\hline \multicolumn{2}{|c|}{ Renda } & Frequência & \% \\
\hline \multirow{4}{*}{ Válidos } & Menos de 1/2 salário mínimo & 4 & 1,7 \\
\cline { 2 - 4 } & $1 / 2$ a 1 salário mínimo & 38 & 16,4 \\
\cline { 2 - 4 } & 1 a $1^{1 / 2}$ salários mínimos & 6 & 2,6 \\
\cline { 2 - 4 } & $1^{1 / 2}$ a 2 salários mínimos & 5 & 2,2 \\
\cline { 2 - 4 } & 2 a 21/2 salários mínimos & 2 & 0,9 \\
\cline { 2 - 4 } & $2^{1 / 2}$ a 3 salários mínimos & 2 & 0,9 \\
\hline Subtotal & 57 & 24,6 \\
\hline Omissos & 175 & 75,4 \\
\hline Total & $\mathbf{2 3 2}$ & $\mathbf{1 0 0 , 0}$ \\
\hline
\end{tabular}

Fonte: Pesquisa de campo 
Outra situação percebida foi a baixa produção e renda informada pelos criadores de bovinos e bubalinos, talvez pela quantidade estabelecida de 20 animais no plano de gestão e/ou pelas medidas repreensivas realizadas pelo ICMBio. Mesmo os números válidos apresentando-se baixos (57 entrevistados), o mercado da pecuária continua em ascensão. Estes dados são confirmados também por alguns analistas do ICMBio:

(...) hoje, a Resex Rio Ouro Preto possui mais de 10 mil bovinos (dados do Idaron de vacina) e a tendência é aumentar (Analista Ambiental/ICMBio, Guajará-Mirim-RO, janeiro 2017).

(...) Apesar disso, a ausência do governo provocou a construção de pastos e criação de gado que cresce a cada ano, lamentavelmente é inacreditável essa situação (Analista Ambiental/ICMBio, Resex Alto Juruá, Cruzeiro do Sul-AC, fevereiro 2012).

(...) A tendência da pecuária é de aumento de criação, mas tentamos controlar em decorrência dos limites jurídicos e territoriais (Analista Ambiental/ICMBio, Brasília-DF, fevereiro 2017).

(...) Precisamos de investimentos maciços, as políticas das Resex estão muito atrasadas, só discurso de gabinete não resolve (Analista Ambiental/ICMBio, Cruzeiro do Sul-AC, março 2012). Confirma essa data. Se for real, corrige.

A pecuária extensiva em Resex, sinaliza a necessidade de investigação adicional e formulação de políticas para o dinamismo e heterogeneidade do uso da terra. A criação de gado de pequena escala tem se transformado em alternativa de geração de renda, que visa suprir necessidades e desejos de moradores (Salisbury \& Schmink, 2007). Além disso, é uma atividade produtiva fácil de vender e traz garantias de segurança ao produtor, e isso não acontece com o extrativismo, que têm preços muito baixos no mercado (Gomes, Vadjunec \& Perz, 2012). Mais ainda, no cotidiano das Resex, muitas famílias comercializam bovinos e bubalinos por ser um retorno menos arriscado (Vadjunec \& Rocheleau, 2009).

\subsection{Produção extrativista}

O extrativismo foi o instrumento mais forte para a criação das Resex, entretanto, sua economia não se manteve estrategicamente no mercado. Os dados mostram que o extrativismo se tornou uma renda complementar à agricultura e pecuária. $\mathrm{O}$ que deveria ser atividade principal se tornou secundária. A renda derivada do extrativismo (castanha, açaí, borracha e óleos vegetais) ficou abaixo de 0,5 salário mínimo, equivalendo 33,6\% dos 99 entrevistados. Os 133 (57,3\%) dos 232 entrevistados (casos omissos) responderam que não trabalham com esta atividade (Tabela 3 ).

Tabela 3: Rendimento domiciliar mensal do extrativismo nas três Resex

\begin{tabular}{|c|c|c|c|}
\hline \multicolumn{2}{|r|}{ Renda } & Frequência & $\%$ \\
\hline \multirow{4}{*}{ Válidos } & Menos de $1 / 2$ salário mínimo & 78 & 33,6 \\
\hline & 1/2 a 1 salário mínimo & 13 & 5,6 \\
\hline & 1 a $1^{1 / 2}$ salários mínimos & 6 & 2,6 \\
\hline & 2 a $2^{1 / 2}$ salários mínimos & 2 & 0,9 \\
\hline \multicolumn{2}{|l|}{ Subtotal } & 99 & 42,7 \\
\hline \multicolumn{2}{|l|}{ Omissos } & 133 & 57,3 \\
\hline \multicolumn{2}{|l|}{ Total } & 232 & 100,0 \\
\hline
\end{tabular}

Fonte: Pesquisa de campo

Os dados indicam que está atividade produtiva está se esgotando, ao caminho do colapso. Todos os esforços de Estado, organizações não-governamentais e de ambientalistas, não surtiram efeito. O extrativismo vem se esfacelando como importante vetor econômico, frente ao crescimento 
da agropecuária e mineração (Clement, 2006). Alguns gestores do ICMBio concluem que o extrativismo pode se exaurir.

(...) A produção e o mercado extrativista são fracos porque não têm iniciativa e investimentos de um profissional capaz de estruturar uma cadeia produtiva, a exemplo de coleta de óleos e essências farmacêuticas (Analista Ambiental/ICMBio, Brasília-DF, fevereiro 2017).

(...) O principal fator de desmatamento foi o declínio do extrativismo, que motivou e intensificou o desmate para criação bovina, bubalina e venda irregular de madeira (Analista Ambiental/Rio Ouro Preto/ICMBio, Guajará-Mirim-RO, fevereiro 2017).

O modelo pode falir, porque não estamos construindo um modelo de longo prazo, não existe uma política de valorização de pessoas, de trabalho extrativista, abertura de crédito e reconhecimento na sociedade (Analista Ambiental/ICMBio, Porto Velho-RO, fevereiro 2017).

Estes resultados contrariam os argumentos de Allegretti (2008) de que a política de criação de Resex teve êxito social porque assegurou meios de vida para gerações atuais e futuras. Os dados dos três sistemas mostram que, além do extrativismo ter se tornado a principal atividade geradora de renda, pela baixa produtividade da terra e da mão de obra, apoiou-se na coleta dos recursos naturais (Homma, 2011).

Para Hall (2004), existem graves problemas em Resex, estes incluem mercados limitados para produtos florestais, vulnerabilidade às flutuações de preços e altos custos de transação, o que torna a autossuficiência econômica irrealista. O extrativismo é ineficiente e não sobreviverá por muito tempo, devido à perda de competitividade frente as outras alternativas econômicas e a migração rural urbana.

A participação das duas atividades que deveriam se desenvolver em pequena escala e com baixa participação na renda (agricultura e pecuária), ambas extensivas, além de se tornarem principais geradoras de renda, se somadas, aumentaram as taxas de desflorestamento (Inpe, 2017). Os dados dos três sistemas produtivos revelam que argumentos que defendiam a criação e manutenção de Resex na Amazônia (Fearnside, 1989; Allegretti, 2008) não se sustentam.

\subsection{Desflorestamento}

Com se verifica (Tabela 4), o desmatamento nas áreas de Resex foi maior do período que vai de 1990 (ano de criação) a 1999. O principal motivo de criação de Resex na Amazônia foi para reduzir os impactos ao meio ambiente, entretanto, os desafios são crescentes para moradores e gestores dessas áreas. Um forte motivo são as precárias condições de vida de seus habitantes, à medida que desenvolvem atividades produtivas que causam degradação ambiental (Riemann, Santesálvarez \& Pombo, 2011).

Dentre os intervalos avaliados, o segundo, terceiro e quarto possuem mais proporcionalidade temporal, mas as oscilações de desflorestamento acontecem em maior e menor nível. Portanto, as Resex continuam desmatando em razão de necessidades e/ou baixa efetividade de políticas públicas de instituições estatais. 
Tabela 4: Desflorestamento nas áreas das Resex

\begin{tabular}{|c|c|c|c|c|}
\hline RESEX & Área Total (ha) & Períodos & Desflorestados (ha) & $\%$ \\
\hline \multirow{5}{*}{$\begin{array}{c}\text { Chico } \\
\text { Mendes (AC) }\end{array}$} & \multirow{5}{*}{$931.537,14$} & Até 1999 & 19.430 & 2,09 \\
\hline & & $2000-2004$ & 17.476 & 1,88 \\
\hline & & $2005-2009$ & 6.356 & 0,68 \\
\hline & & $2010-2015$ & 8.037 & 0,86 \\
\hline & & & 51.299 & $\mathbf{5 , 5 1}$ \\
\hline \multirow{5}{*}{$\begin{array}{c}\text { Alto } \\
\text { Juruá (AC) }\end{array}$} & \multirow{5}{*}{$537.946,47$} & Até 1999 & 6.540 & 1,22 \\
\hline & & $2000-2004$ & 4.418 & 0,82 \\
\hline & & $2005-2009$ & 1.745 & 0,32 \\
\hline & & 2010-2015 & 3.778 & 0,70 \\
\hline & & & 16.481 & $\mathbf{3 , 0 6}$ \\
\hline \multirow{5}{*}{$\begin{array}{l}\text { Rio Ouro } \\
\text { Preto (RO) }\end{array}$} & \multirow{5}{*}{$204.631,55$} & Até 1999 & 7.730 & 3,78 \\
\hline & & $2000-2004$ & 7.746 & 3,79 \\
\hline & & $2005-2009$ & 2.811 & 1,37 \\
\hline & & $2010-2015$ & 1.332 & 0,65 \\
\hline & & & 19.619 & 9,59 \\
\hline \multirow{5}{*}{$\begin{array}{c}\text { Rio } \\
\text { Cajari (AP) }\end{array}$} & \multirow{5}{*}{$532.397,20$} & Até 1999 & 7.720 & 1,45 \\
\hline & & $2000-2004$ & 1.220 & 0,23 \\
\hline & & $2005-2009$ & 1.949 & 0,37 \\
\hline & & $2010-2015$ & 1001 & 0,19 \\
\hline & & & 11.890 & 2,23 \\
\hline
\end{tabular}

Fonte: Adaptado do Inpe (2017)

Em se tratando do segundo período (2000-2004), somente a Resex Rio Ouro Preto superou o primeiro período, as demais indicaram redução. No terceiro período (2005-2009), houve queda em relação ao segundo, exceto a Resex Rio Cajari, que acumulou diferença de $0,14 \%$. O mesmo ocorreu com o quarto período (2010-2015), uma vez que a Resex Chico Mendes desflorestou 0,18\% e a Alto Juruá de $0,38 \%$, em relação ao terceiro intervalo.

Peres (2011) apresentou dado semelhante ao declarar que a Reserva Extrativista Chico Mendes foi desmatada 6,3\% dos 931.537 hectares para acomodar 10 mil cabeças de gado, uma expansão de 11 vezes a área desflorestada para pastagem desde que a reserva foi criada (1990).

Outro exemplo foi a Resex Alto Juruá, que aumentou desmatamento marginal permanente per capita de 0,49 ha para 1,1 ha entre 1989 a 2000 (Ruiz-Pérez et al., 2005). Ainda, segundo o autor, o desmatamento temporário está associado a coivara e agricultura de pequena escala. Essas conclusões são reforçadas por Homma (2016), ao confirmar que o elevado desmatamento é proveniente de atividades da pecuária e agricultura.

Em escala mundial, se o objetivo é reduzir o desmatamento e as queimadas em florestas primárias da Amazônia, há necessidade de analisar as políticas públicas de forma mais ampla (Brown; Rosendo, 2000b), para que favoreçam o uso dessas áreas já desmatadas da região (Homma, 1996), e melhor compreensão dos desafios das Resex (Levey, 2002). É necessário questionar a imagem equivocada de êxito (Allegretti, 2008), ou de uma estratégia prioritária ambiental equivocada, que busca a melhoria de condições de vida dos habitantes, posteriormente (Fearnside, 1989). Quase três décadas depois de criação de Resex, os objetivos triplo de sustentabilidade não foram alcançados.

\subsection{Fracasso do modelo Resex}

A política de demarcação das Resex visou atenuar a pressão humana destas áreas. Além disso, se precipitou quando não assumiu a política ambiental, à proporção que deixou sob comando externo, na década de 1990. A proposta formulada pelos seringueiros na década de 1980 enfatizava 
uma reforma agrária diferenciada, em particulardas que eram criadas pelo Instituto Nacional de Colonização e Reforma Agrária (Incra).

Entre os pontos relatados na proposta das Resex, o de maior destaque confirmava a necessidade de vivência harmoniosa com a natureza, isto é a conservação e o desenvolvimento caminhariam racionalmente em plena sintonia. $\mathrm{O}$ resultado foi que as famílias que habitam nas áreas transformadas em Resex ficaram politicamente isoladas, prejudicadas a subsistência, e com pouca capacidade de influenciar o planejamento e gestão (Santos \& Brannstrom, 2015).

Hoje a prioridade é outra, onde, por imposições de mercado, os produtores estão procurando promover o esverdeamento das atividades, não por pressões ambientais ou imposições legais. A demarcação de áreas para conservação atendeu aspirações de ONGs e movimentos ambientalistas, bem como gerou muitos debates científicos e políticos.

No entanto, ainda faltam: a) melhorar as condições socioeconômicas dos habitantes das áreas de Resex; b) reduzir as taxas de desmatamento nessas áreas; c) diminuir a ineficiência de planejamento e gestão de organizações responsáveis pelas políticas ambientais para Amazônia; d) integrar políticas de crédito (como Pronaf), de assentamentos (como as do Incra), fiscalização e gestão do Ibama e ICMBio); e) Efetivar políticas de combate a pobreza, pois, como argumentam Siraj et al. (2016), recursos florestais ofertam meios de subsistência aos pobres de todo o mundo e práticas ilegais são forma de superar pobreza. Desse modo, as ações do Estado mostraram uma realidade inversa quase 30 anos depois.

\section{CONSIDERAÇÕES FINAIS}

As políticas sociais e produtivas se mostraram ineficazes quase 30 anos após sua concepção. A tendência é de demarcação de territórios a conservação, mas não significa melhoria nas condições de vida de milhares de famílias dessas áreas. O desgaste promovido pela intervenção governamental não respeitou os protagonistas (seringueiros, castanheiros, etc.) de Resex na Amazônia (Freitas \& Rivas, 2014).

O abandono estatal das famílias que estão nestas áreas é visível e parece ocorrer propositalmente, como estratégia de redução do número de moradores. Como não detém amparo jurídico para retirá-las, o que vem se mostrando mais cômodo é não alocar recursos sociais e produtivos, especialmente, para fiscalizações.

A renda procedente da agricultura e pecuária são semelhantes em termos de rendimentos, pois a renda domiciliar mensal nas três Resex ficou entre $1 / 2$ a 1 salário mínimo, já o extrativismo apresenta faturamento abaixo de $1 / 2$ salário mínimo. Tanto o crescimento agrícola e pecuário, quanto a queda do extrativismo são decorrentes da falta de ação eficiente de organizações estatais. $O$ desmatamento está associado a estas necessidades, tais como alimentação, vestimentas, água potável, medicamentos, materiais escolares, meio de transporte, etc.

Então, porque o Estado Nacional criou Resex para proteger os recursos ambientais e não para o atendimento de necessidades sociais e produtivas que visem o desenvolvimento humano? As elevadas demandas sociais dos moradores, a baixa rentabilidade das atividades extrativas, os elevados custos de manutenção e o baixo investimento de infraestrutura vêm provocando dificuldades para a sustentabilidade das Resex.

Os resultados principais revelam que as Resex são insustentáveis porque foram criadas com ênfase na conservação e não para desenvolver de forma sustentável seus moradores. Outrossim, a migração de crianças e jovens das Resex para zonas urbanas constitui outra incógnita com relação a sustentabilidade em médio e longo prazo, porque no futuro estas áreas poderão ficar sem habitantes. A insustentabilidade acontece de forma induzida e não sabemos se é intencional a escassez de recursos humanos e financeiros.

A título de alternativa, agricultura com o mínimo de tecnologias em áreas degradadas passa ser defendida como possibilidade estratégica à racionalização em Unidades de Conservação de uso sustentável. Mais ainda, não é ideia recente aproveitar áreas desmatadas para outras culturas mais 
rentáveis que o extrativismo. Assim, a necessidade de políticas voltadas para a viabilidade econômica da Resex justa e eficiente será viável se houver investimento em processos produtivos menos complexos e em cadeias voltadas para populações tradicionais, nem sempre viáveis (Negret, 2010).

Entre os problemas citados, o desafio é transformar pelo menos parte da Segunda Natureza representada pelas áreas desmatadas nas Resex em uma Terceira Natureza com atividades produtivas mais sustentáveis que gerem renda e emprego (Homma, 2014). A floresta intocada é a Primeira Natureza. Em primeira instância, haverá necessidade de relações de confiança forte e democráticas, assim como a inclusão de alternativas econômicas viáveis combinadas ao equilíbrio ecossistêmico.

Nestas circunstâncias atuais, novas pesquisas podem revelar evidência em outras áreas e regiões do país para verificar se esse é um resultado inesperado ou intencional. Se é exclusividade da Amazônia ou ocorre também em outras regiões do país. A outra vertente de estudo seria efetuar uma comparação entre Resex e as Reservas de Desenvolvimento Sustentável (RDS). Também foi possível demonstrar que, para alcançar desenvolvimento e conservação dessas áreas, é necessário reformular as políticas públicas atuais, dando atenção, primordialmente, a seus residentes. A inversão de prioridades é indispensável.

\section{NOTA}

${ }^{1}$ Vislumbram desenvolvimento sustentável com base na harmonia do ser humano com a natureza, portanto, são áreas que objetivam equilíbrio de conservação ambiental e desenvolvimento social.

\section{REFERÊNCIAS}

Allegretti, M.(1994) Políticas para o uso dos recursos naturais renováveis. In: Clüsener-Godt, M., Sachs, I.(Org.). Extractivismo na Amazônia Brasileira: perspectivas sobre o desenvolvimento regional. Paris: Compêndio MAB, Unesco, 145-162.

allegretti, M. (2008) A construção social de políticas públicas: Chico Mendes e o movimento dos seringueiros. Desenvolvimento e Meio Ambiente, Curitiba 18(12), 39-59.

Arruda, R. S. V. (1999) Populações tradicionais e a proteção dos recursos naturais em unidades de conservação. Ambiente e Sociedade, 2(5), 79-92.

Babbie, E. (2003) Método de pesquisa survey. Belo Horizonte: UFMG.

Begon, M., Townsend, C. R., Harper, J. L. (2005) Ecology: from individuals to ecosystems. (4. ed.) Malden: Blackwell Publishing, 738 p.

Begossi, A., Silvano, R. A. M., Amaral, B. D., Oyakawa, O. T. (1999) Uses of fish and game by inhabitants of an Acre, Brazil Extractive Reserve (Upper Jurua, Acre, Brazil). Environment, Development and Sustainability, Belgium, 1, 73-93.

Benatti, H. D. (1998) Unidades de conservação e populações tradicionais: uma análise jurídica da realidade brasileira. Paper do Naea, (98), 2-19.

Browder, J. (1992) The limits of extractivism: tropical forest strategies beyond extractive reserves. BioScience, Uberlândia, 42(3), 166-174. 
Brown, K., Rosendo, S. (2000) The institutional architecture of extractive reserves in Rondônia, Brazil. The Geographical Journal, Malden, 166(1), 35-48.

Campos-Silva, J., Peres, C. (2016) Community-based management induces rapid recovery of a high-value tropical freshwater fishery. Scientific Reports, 6, 1-13.

Carmenta, R., Blackburn, G. A., Davies, G., Sassi, C., Lima, A., Parry, L., Tych, W., Barlow, J. (2016) Does the establishment of sustainable use reserves affect fire management in the humid tropics. PLoS ONE, San Francisco, 11(2), 1-20.

Carmo, J., Pires, M., Jesus Júnior, G., Cavalcante, A., Trevizan, S. (2016) Voz da natureza e da mulher na Resex de Canavieiras-Bahia-Brasil: sustentabilidade ambiental e de gênero na perspectiva do ecofeminismo. Estudos Feministas, Florianópolis, 24(1), 155-180.

Carregosa, A. E., Silva, C. S., Kunhavalik, P. J. (2015) Unidade de conservção e comunidade local: uma relação em construção. Desenvolvimento e Meio Ambiente, 35, 305-319.

Clement, C. (2006) A lógica do mercado e o futuro da produção extrativista. In: Kubo, R., Bassi, J., Souza, G., Alencar, N., P.M. Medeiros, P., Albuquerque, P.(orgs.). Atualidades em etnobiologia e etnoecologia. Recife: Nupeea/Sbee, 135-150.

Coriolano, L. N. M., Lima, L. C. (2003) Turismo comunitário e responsabilidades socioambiental. ( $1^{\mathrm{a}}$ ed.) Ceará: Eduece.

Fantini, C. A., Crisóstomo, F. C. (2009) Conflitos de interesses em torno da exploração madeireira na reserva extrativista Chico Mendes, Acre, Brasil. Boletim do Museu Paraense Emílio Goeldi, Belém, 4(2), 1-17.

Fearnside, P. M. (1989) Extractive reserves in Brazilian Amazonia: an opportunity to maintain tropical rain forest under sustainable use. BioScience, Uberlândia, 39(6), 39-42.

Florentino, G., Silva, D., Freitas, J. (2016) Análise de reservas extrativistas a partir da economia ecológica. Observatorio de La Economía Latinoamericana, Málaga, 16, 2-10.

Freitas, J., Rivas, A. (2014) Unidades de conservação promovem pobreza e estimulam agressão a natureza. Revista de Gestão Social e Ambiental - RGSA, São Paulo, 8(3), 18-34.

Goeschl, T., Igliori, D. C. (2004) Reconciling conservation and development: a dynamic hotelling model of extractive reserves. Land Economics, Madison, 80(3), 340-354.

Gomes, C. V. A., Vadjunec, J. M., Perz, S. G. (2012) Rubber tapper identities: political-economic dynamics, livelihood shifts, and environmental implications in a changing Amazon. Geoforum, Dublin, 43(2), 260-271.

Hall, A. (2004) Extractive reserves: building natural assets in the Brazilian Amazon. Political Economy Research Institute, Massachusetts, 74, 2-27.

Homma, A. K. O.(1996) Modernisation and technological dualism in the extractive economy in Amazonia. In: Ruiz Péres, M., Arnold, J(Org.). (1996) Current issues in non-timber forest products research. Indonésia: Center for International Forestry Research, 59-81. 
Homma, A. K. O. (2003) História da Agricultura na Amazônia: da era pré-colombiana ao terceiro milênio. Brasília: Embrapa. 274 p.

Homma, A. K. O. (2010) Política agrícola ou política ambiental para resolver os problemas da Amazônia? Política Agrícola, Brasília, 9(1), 91-102.

Homma, A. K. O. (2011) Biodiversidade e Biopirataria na Amazônia: como reduzir os riscos? Passages de Paris, Paris, 6, 111-128.

Homma, A. K. O. (2014) Extrativismo vegetal na Amazônia: história, ecologia, economia e domesticação. Brasília: Embrapa. 468 p.

Homma, A. K. O. (2016) A imigração japonesa na Amazônia: sua contribuição ao desenvolvimento agrícola. Brasília: Embrapa, (2 ed.), 255p.

Homma, A.K.O.(2017) A terceira natureza da Amazônia. Revista Paranaense de Desenvolvimento, Curitiba, 38(132), 27-42, jan./jun.

Inpe. Instituto de Pesquisas Espaciais. (2017) Desflorestamento na Amazônia, Inpe/Prodes. Recuperado em: maio de 2017, de://www.inpe.dpi/inpe.prodes/html.

Lage, B. H. G., Milone, P. C. (2001) Economia do turismo, (7ª ed.) São Paulo: Atlas. 226 p.

Levey, D. J. (2002) Prospects for conserving biodiversity in Amazonian extractive reserves. Ecology Letters, Washington, 5, 320-324.

Maciel, R. C. G., Reydon, B. P., Costa, J. A., Sales, G. (2010) Pagando pelos serviços ambientais: uma proposta para a reserva extrativista Chico Mendes. Acta Amazonica, Manaus, 40(3), 489-498.

Moher, D., Liberati, A., Tetzlaff, J., Altman, D. G. (2009) Preferred reporting items for systematic reviews and meta-analyses: the prisma statement. PlosMedicine, San Francisco, 151(4), 1-6.

Newton, P., Endo, W., Peres, C. A. (2011) Determinants of livelihood strategy variation in two extractive reserves in amazonian flooded and unflooded forests. Environmental Conservation, Cambridge, 39(2), 97-110.

Peres, C. A. (2011) Conservation in sustainable-use tropical forest reserves. Conservation Biology, Washington, 25(6), 1124-1129.

Riemann, H., Santesálvarez, R., Pombo, A. (2011) El papel de las áreas naturales protegidas en el desarrollo local: el caso de la península de Baja California. Gestión y Política Pública, Cidade do México, 20(2), 1-13.

Ruiz-Pérez, M., Almeida, M., Dewi, S., Costa, E. M. L., Pantoja, M. C., Puntodewo, A., Postigo, A. A., Andrade, A. G. (2005) Conservation and development in amazonian extractive reserves: the case of Alto Juruá. BioOne, Washington, 34(3), 218-223.

Salafsky, N., Dugelby, B., Terborgh, J. (1993) Can extractive reserves save the rain forest? An ecological and socioeconomic comparison of nontimber forest product extraction systems in Peten, Guatemala, and west kalimantan, Indonesia. Conservation Biology, Washington, 7(1), 39-52. 
Salisbury, D. S., Schmink, M. (2007) Cows versus rubber: changing livelihoods among Amazonian extractivists. Geoforum, Dublin, 38(6), 1233-1249.

Santos, N. A., Brannstrom, C. (2015) Livelihood strategies in a marine extractive reserve: implications for conservation interventions. Marine Policy, Cardiff, 59, 45-52.

Silva, C., Fraxe, T., Silva, M.(2015) Potencial arqueológico do Baixo Rio Purus/AM: um estudo preliminar. In: Pereira, H., Fraxe, T., Costa, F., Witkoski, A. (Org.). Unidades de conservação do Amazonas no Interflúvio Purus-Madeira: diversidade cultural e gestão social dos bens comuns. Manaus: Edua, 171-186.

Siraj-Blatchford, J., Mogharreban, C., Park, E. (2016) International research on education for sustainable development in early childhood. International Perspectives on Early, 1-15.

Vadjunec, J. M. (2011) Extracting a Livelihood: institutional and social dimensions of deforestation in the Chico Mendes extractive reserve, Acre, Brazil. Journal of Latin American Geography, Texas, $10(1), 151-174$.

Vadjunec, J., Rocheleau, D. (2009) Beyond forest cover: land use and biodiversity in rubber trail forests of the Chico Mendes extractive reserve. Ecology and Society, Wolfville, 14(2), 1-29.

Vivacqua, M., Vieira, P. F. (2005) Conflitos socioambientais em Unidades de Conservação. Política e Sociedade, 4(7), 139-162.

Volpato, L. G. (2015) O método lógico para redação científica. Revista Eletrônica de Comunicação Informação \& Inovação em Saúde, 9(1), 1-14.

Data da submissão: 16/05/2017

Data de aceite: 18/12/2017 